\title{
Plagio en textos académicos
}

\author{
Plagiarism in Academic Texts
}

\author{
Marta Eugenia Rojas Porras ${ }^{1}$ \\ Catedrática jubilada \\ Universidad de Costa Rica \\ San José, Costa Rica \\ merojasporras@yahoo.com
}

Recibido 10 de noviembre de 2011 • Corregido 22 de junio de 2012 • Aceptado 28 de junio de 2012

Resumen. Resulta innegable la responsabilidad ética y social de dar crédito a las fuentes que sirven de base para el trabajo científico y artístico. En este documento se aborda, de manera inicial, la temática sobre el plagio académico, se conceptualizan diversas formas de este y se describe lo encontrado, al respecto, en un análisis pericial. El propósito de esta colaboración es llamar la atención sobre uno de los cuidados necesarios en el texto que se escribe y se publica. Se espera que sea de provecho para iniciar una discusión sobre el tema.

Palabras claves. Plagio, texto académico, cita textual, parafraseo

Abstract. The ethical and social responsibility of citing the sources in a scientific or artistic work is undeniable. This paper explores, in a preliminary way, academic plagiarism in its various forms. It includes findings based on a forensic analysis. The purpose of this paper is to raise awareness on the importance of considering these details when writing and publishing a text. Hopefully, this analysis may put the issue under discussion.

Keywords. Plagiarism, academic text, direct quote, paraphrasing.

\footnotetext{
Licenciada en Filología Española y Magíster en Lingüística de la Universidad de Costa Rica. Actualmente catedrática jubilada. Ejerció por 25 años como docente en la Escuela de Filología, Lingüística y Literatura e investigadora en el Instituto de Investigación en Educación (INIE), de la Universidad de Costa Rica. Durante 12 años fue la directora de la Revista Educación y actualmente miembro de su Consejo Editorial. Posee publicaciones en revistas nacionales e internacionales. En coautoría y derivados de la investigación tiene 6 libros editados por la Editorial UCR. Además, en el género de textos didácticos: 3 libros Despertando a las palabras, (1983, ECR); 9 libros de Español de la Serie: Hacia el siglo XXI, proyecto que también coordinó (1996, EUCR), y 6 libros Palabras juguetonas. Dinámicas con léxico escolar gradual (2011, EUCR). En su obra también constan 3 poemarios: La sonrisa de Penélope y su costumbre del adiós, Aposentos del deseo y Habitar la casa del tesoro.
} 


\section{Introducción}

Por encargo de una instancia universitaria, quien escribe estas líneas llevó a cabo un análisis pericial en documentos académicos sospechosos de plagio, una labor nueva en el país y de la cual casi no hay antecedentes. Debido a la importancia de reflexionar sobre esta temática, relevante tanto para revistas científicas como para instituciones formales de valoración y acreditación de los trabajos escritos, se decidió compartir sobre la experiencia dicha.

La responsabilidad de dar crédito a los autores o autoras, cuyos textos o ideas se utilizan en el escrito, constituye una obligación ética de consenso en el ámbito académico y social. Desde tiempos escolares se aprende sobre el uso de comillas como signo de puntuación para anotar palabras, frases y párrafos ajenos.

Dado el auge delas comunicaciones en Internet, se ha hechonecesario tomar una seriede medidas para garantizar los derechos de autoría y el sano y respetuoso uso de la información. En tiempos en los que ya casi todo está dicho, la originalidad se concibe como una máxima de calidad que constituye en plantear en el texto escrito solo aquello de lo que se tenga evidencia, señalar debidamente las fuentes del conocimiento desde donde se parte y hacerlo de manera clara, organizada y precisa.

Como ya se dijo, en los trabajos científicos es obligación citar autores y obras de las que se toman datos, opiniones, ideas, teorías, etc., con lo cual se cumple no solo "(...) con una tradición académica, sino, también, con las exigencias contenidas en un precepto legal” (Sánchez, 2006, p. 80).

(...) Dado el libre intercambio de ideas, que es tan importante para la salud del discurso intelectual, los autores tal vez no sepan dónde se originó la idea para su estudio. Sin embargo, si los autores lo saben, deben dar crédito a la fuente. Esto incluye las comunicaciones personales (...). (APA, 2010, p. 16)

En este sentido "(...) un mismo tema puede ser tratado, por distintos autores, en infinidad de ocasiones sin que con ello pueda afirmarse que necesariamente existirá plagio (...)" (Balbuena, s. f., 1.1. Antecedentes históricos, párr. 13). Por lo anterior, resulta relevante reconocer las ocasiones en que este ocurre.

El plagio constituye una acción en la que quien "(...) copia ilícitamente se atribuye la paternidad de la obra (...)" (Sánchez, 2006, p. 68).

En otros términos:

El plagio implica el préstamo intencionado de una idea y/o [sic] la copia intencionada del texto (lingüístico, musical, etc.) utilizado para expresar esta idea, para esconder la falta de originalidad en una producción lingüística determinada. Por lo tanto, parece que el elemento determinante en la caracterización del plagio a veces es la idea, a veces el texto lingüístico, y otras veces los dos elementos. (Laboratorio de Lingüística Forens [ForensicLab], s. f., párr. 4) 
Barrón (2010) plantea que, cuando se habla de texto (no olvidar que existe plagio de imágenes, videos y sonido, entre muchas otras cosas), "(...) plagiar significa incluir en un documento fragmentos de textos escritos por alguna otra persona sin darle el crédito adecuado. Esta falta ha mostrado en los últimos años una explosión en el número de casos. La razón es sencilla: hoy en día tenemos acceso a un enorme repositorio de información entre páginas especializadas, bibliotecas digitales y enciclopedias digitales (...)" (párr. 3).

Existen dos formas válidas de anotar, responsablemente, las obras que sirven de referente al trabajo que se realiza: una representada por la reproducción textual y la otra por el parafraseo. Tanto cuando se reproducen textualmente, como cuando se resume o parafrasea, resulta indispensable hacer constar la fuente, para lo cual hay todo un sistema o protocolo por atender.

Tello y Zepada (s. f.), basadas en Hexham, realizan la presentación El plagio académico, en la que conceptualizan diversas formas de este, las cuales, a continuación, se resumen:

\section{Plagio directo:}

Se incurre en este tipo cuando:

- Se omite la autoría y no se indica con comillas lo tomado.

- Se realizan cambios mínimos en el texto de otro (se modifica la estructura de la oración, se sustituyen minúsculas por mayúsculas o viceversa, se usan sinónimos, etc.) y se presenta como original.

\section{Plagio por el uso inadecuado de la paráfrasis}

- Aunque se anota la autoría, el plagio se presenta porque el texto original se reproduce con unos pocos cambios que no constituyen paráfrasis.

\section{Plagio complejo usando una referencia}

- Existe la referencia de autoría original, pero se señalan con inexactitud las páginas de la fuente.

- Parafraseo en que se resumen textos extensos, pero con muy poca o ninguna indicación de que corresponden a paráfrasis.

- Ausencia de comillas en palabras y frases del texto original que se reproducen textualmente.

\section{Plagio con comillas sueltas}

- Se comete cuando se continúa reproduciendo una cita textual una vez que se han cerrado comillas o cuando se omite que las frases anteriores corresponden a la misma cita. 
URL: http://www.una.ac.cr/educare

\section{El parafraseo como plagio}

Ocurre cuando:

- Se parafrasea y no se anota la referencia de la fuente original.

- El parafraseo es continuo y extenso, no se añade material que permita interacción o enriquezca la información, a pesar de que se menciona la fuente.

- Los trabajos académicos - que exigen pensamientos originales y reflexiones críticas sobre los puntos de vista de otras personas- se convierten en textos que no superan la repetición.

- No se identifican claramente, como tales, los pasajes parafraseados.

\section{El parafraseo no se considera plagio cuando:}

- No domina por sobre el trabajo de quien escribe.

- Se utiliza para permitir al autor interactuar críticamente con los puntos de vista de otra persona.

- El argumento del texto original es re-escrito en palabras diferentes.

\section{El "auto-plagio" o fraude de reciclaje}

Se comete "auto-plagio" o fraude de reciclaje cuando:

- Se le cambia la apariencia a un trabajo y se presenta como si fuera otro distinto.

- Se omite la indicación de que el trabajo está siendo reciclado.

\section{Citar el conocimiento de dominio público no es plagio}

Lo que todoel mundo sabeno es plagioy no requiere cita de sufuente, pero síresulta indispensable cuidar que si ya está escrito, el documento que se elabora no coincida textualmente con el otro. Difícilmente, cuando se produce el propio texto de manera independiente, se concuerde en estructuras gramaticales y formas de desarrollo de las ideas.

Respecto a los sistemas de detección del plagio, Comas y Sureda (2007) plantean dos tipos: a) basado en la experiencia y análisis del docente y b) mediante instrumentos tecnológicos (McLafferty y Foust, 2004).

En cuanto al primer tipo, los docentes deben prestar atención a los siguientes aspectos:

- Incongruencia entre ideas, teorías e hipótesis expresadas en el trabajo.

- Incongruencia en los estilos de escritura (narración, usos gramaticales, etc.) dentro del texto. 
- Incongruencia en el desarrollo "lógico" del trabajo.

- Incongruencia entre las ideas, teorías, hipótesis, etc. presentadas por el alumno y trabajos anteriores del mismo.

- Incongruencia en la bibliografía y fuentes citadas.

- Incongruencia en el formato de presentación (por ejemplo: existencia de saltos de página incorrectos; existencia de diferentes tipos de fuente, tamaño, etc.; existencia de números de página no consecutivos, etc.)

- Incongruencia en las citas (Comas y Sureda, 2007, Causas asociadas al fenómeno del ciber-plagio y posibles soluciones, párr. 6)

Por su parte, el Laboratorio de Lingüística Forense, del Institut Universitari de Lingüística Aplicada, ente especializado en la detección del plagio de ideas o textos en escritos que tratan el mismo tema y el plagio entre traducciones, utiliza un protocolo con las siguientes actividades:

- Establecer las "marcas" lingüísticas y los criterios que pueden ser determinantes en casos de plagio.

- Responder a una pregunta empírica general: ¿qué grado de similitud tienen que reflejar dos o más textos antes de poder decidir si han sido plagiados por otro? ¿qué grado de similitud / diferencia es suficiente?

- Establecer el nivel umbral de similitud necesario y el punto exacto en que este nivel de similitud se convierte en sospechoso.

- Indicar la rareza o expectativa de las elecciones hechas por los autores de textos y traducciones, para establecer la idiosincrasia o la coincidencia de los textos producidos, algo que solo puede ser establecido a partir de corpus y bancos de datos de referencia.

- Introducir en la discusión y presentación del peritaje el posible contraataque de la parte contraria en respuesta a la evidencia presentada por nuestro laboratorio.

- Responder a otra cuestión fundamental: si las pruebas presentadas pueden ayudar a establecer un caso prima facie, es decir, un caso en cuyo contexto las pruebas son suficientes para que el juez o el tribunal pueda dictar sentencia. (Laboratorio de Lingüística Forense, s. f., párr. 6) 
URL: http://www.una.ac.cr/educare

Se informa, en el mismo texto, que para establecer la existencia de plagio, este laboratorio

(...) utiliza la última versión de la aplicación informática CopyCatch (CopyCatch Gold), diseñada por David Woolls, de CFL Software Development. Esta herramienta puede tratar textos de muchos tipos y permite un procesamiento muy rápido de los datos para identificar la similitud textual. El tratamiento permite mostrar el vocabulario coincidente, las correspondencias sintagmáticas y oracionales, y algunos resultados estadísticos. Además, cada pareja de textos analizados queda marcada para mostrar la forma en que el vocabulario, los sintagmas y las oraciones coincidentes aparecen en los textos. El uso de evidencia lingüística cuantitativa (VARBRUL 2 y 3; GOLDVARB 2001) ayuda al analista en su peritaje y añade validez interna y externa a su investigación y, consecuentemente, también a las pruebas que presenta en los juicios. (Laboratorio de Lingüística Forense, s. f., párr. 7)

Las principales medidas analíticas que utilizan son:

\section{- Vocabulario coincidente}

- Palabras únicas compartidas: aquellos vocablos registrados solo una vez en cada documento, pero que aparecen en los dos textos comparados. Cuanta más palabras en esta condición, más alto el grado de similitud.

- Vocabulario único: el número de palabras no compartidas, es decir, únicas dentro de cada texto. Se asume que textos independientes incluirán una proporción más alta de unidades léxicas únicas que aquellos textos dependientes.

- Frases únicas compartidas: frases que se anotan solo una vez en cada documento, pero aparecen en los dos. Cuantas más frases en esta condición, más alto será también el grado de similitud.

Según Barrón (2010), en la actualidad, el desarrollo de métodos que faciliten la detección de plagio cobra relevancia, porque la fuente del plagio, cuya recuperación es imprescindible, resulta difícil de encontrar en un sinnúmero de documentos perdidos en la Web.

Así, son necesarias comparaciones exhaustivas entre documentos para determinar el plagio o la originalidad. Dicha comparación ya es complicada, pero lo es aún más 
cuando el plagio ha implicado alguna modificación, pues se debe identificar la relación semántica de estos.

Hemos aplicado, basados en las propuestas de Lyon y otros investigadores, un enfoque de comparación de texto codificado en forma de $n$-gramas. Codificar un texto en $n$-gramas implica extraer de él fragmentos traslapados de palabras de longitud n. Así, los 2-gramas de "esto es un ejemplo" son "esto es", "es un" y "un ejemplo". Experimentalmente se ha observado que dos documentos, aún cuando han sido producidos por el mismo autor y sobre el mismo tema, suelen tener una baja concentración de $n$-gramas en común, por lo que encontrar varios en dos documentos presumiblemente independientes, lleva a sospechar sobre un reuso de información y sin el crédito adecuado, un caso de plagio. (Barrón, 2010, párr. 6)

Acepta, el mismo autor, que

(...) este tipo de comparaciones entre textos es computacionalmente costosa y en ocasiones entrega resultados con mucho ruido (falsas sospechas de plagio). Por ello, hemos propuesto un método para, dado un documento sospechoso, recuperar buenos candidatos a ser fuente de sus posibles plagios. El método, basado en la selección de palabras relevantes para el documento sospechoso y su búsqueda en el conjunto de potenciales fuentes, ha demostrado no solo acelerar el proceso sino, lo que es más importante, mejorar la salida obtenida. (Barrón, 2010, párr. 7)

No obstante su costo, en la actualidad existe bastante investigación sobre este respecto e incluso hay disponibles diversas herramientas en línea, de uso gratuito, que identifican casos de plagio en un documento.

\section{Metodología utilizada}

\section{Instrumentos}

1. Con base en los estudios anteriormente citados, se elaboró un instrumento elaborado para rendir un informe pericial del supuesto plagio en documentos académicos escritos que tomó en consideración los criterios planteados en la siguiente tabla: 
URL: http://www.una.ac.cr/educare

Instrumento elaborado para rendir un informe pericial del supuesto plagio en documentos académicos escritos

\begin{tabular}{|c|c|c|c|}
\hline Criterios & $\begin{array}{l}\text { Como aparece en la } \\
\text { supuesta fuente }\end{array}$ & $\begin{array}{l}\text { Como aparece en el } \\
\text { texto evaluado }\end{array}$ & $\begin{array}{l}\text { Comentario de } \\
\text { analista }\end{array}$ \\
\hline \multicolumn{4}{|c|}{$\begin{array}{l}\text { Identificación de la(s) supuesta(s) } \\
\text { fuente(s) del plagio }\end{array}$} \\
\hline \multicolumn{4}{|l|}{$\begin{array}{l}\text { Identificación de las fechas de } \\
\text { recepción y aprobación de los } \\
\text { documentos }\end{array}$} \\
\hline \multicolumn{4}{|l|}{$\begin{array}{l}\text { Identificación de copias textuales } \\
\text { de textos ajenos en los que se } \\
\text { omite la autoría o las comillas }\end{array}$} \\
\hline \multicolumn{4}{|l|}{$\begin{array}{l}\text { Identificación de señalamiento } \\
\text { incompleto de la(s) citas(s) }\end{array}$} \\
\hline \multicolumn{4}{|l|}{$\begin{array}{l}\text { Identificación del parafraseo } \\
\text { inadecuado }\end{array}$} \\
\hline \multicolumn{4}{|l|}{$\begin{array}{l}\text { Identificación de información de } \\
\text { conocimiento público que no } \\
\text { constituye plagio }\end{array}$} \\
\hline \multicolumn{4}{|l|}{$\begin{array}{l}\text { Identificación del vocabulario } \\
\text { coincidente }\end{array}$} \\
\hline \multicolumn{4}{|l|}{$\begin{array}{l}\text { Identificación de las palabras } \\
\text { únicas compartidas }\end{array}$} \\
\hline \multicolumn{4}{|l|}{$\begin{array}{l}\text { Identificación del vocabulario } \\
\text { único }\end{array}$} \\
\hline $\begin{array}{l}\text { Identificación de frases únicas } \\
\text { compartidas }\end{array}$ & & & \\
\hline
\end{tabular}

Respecto de esta tabla, la que realmente se validó con este trabajo, no se indagaron los cuatro últimos criterios, debido a que se identifican varias posibles fuentes de posible plagio, las cuales no constituyen obras completas sino párrafos o grupos de párrafos de textos dados.

2. Programas de detector de plagio utilizados:

The Plagirism Checker

Google

CopioNic 


\section{Procedimientos}

1. La primera tarea consistió en obtener los documentos sospechosos de plagio:

Uno se consiguió en formato PDF en la Web, por tanto hubo que someterlo al proceso de convertirlo en Word para la manipulación requerida para el análisis. Otro, publicado solo en formato impreso, se consiguió mediante visitas a bibliotecas, escuelas de la especialidad y a la revista donde se publicó. Este se tuvo que digitar, pues solo de esa manera se podían aplicar los programas de detección de plagio.

2. Se aplicó, a párrafo por párrafo de cada artículo, el programa "The Plagirism Checker". A cada frase identificada como sospechosa por este programa se le dio seguimiento en Google. Cuando se detectó un grupo de párrafos provenientes de un texto, se le aplicó el programa CopioNic, que compara los dos textos y establece un porcentaje de plagio (la limitación de este programa es que solo identifica como plagio el que es textual).

3. Se trasladó cada párrafo de cada artículo a una tabla de dos columnas. En una columna se copiaron los párrafos de cada artículo y en la otra los textos donde aparecían posibles fuentes y las fuentes de la Web donde se alojaban.

4. Se comparó cada párrafo marcando en ambos las coincidencias. Se analizó la comparación y se determinó si el párrafo se considera original o sospechoso.

5. En cada párrafo considerado sospechoso de plagio se realiza una caracterización de lo encontrado.

6. Esta información se traslada a las tablas Análisis, párrafo a párrafo, de coincidencias con otros textos escritos.

7. Se establece un porcentaje de párrafos identificados como coincidentes con otros textos en relación con el total de párrafos del artículo analizado.

8. Se señalan los porcentajes de plagio entre partes de textos comparados, según CopioNic.

\section{Presentación de los datos}

Los datos, para cada artículo, se presentaron en las tablas descriptivas:

- Análisis, párrafo a párrafo, de coincidencias con otros textos escritos

- Análisis porcentual de párrafos en los que aparecen coincidencias con otros textos

- Análisis porcentual de coincidencias entre textos comparados

- En cada caso se realiza una síntesis de lo encontrado 
URL: http://www.una.ac.cr/educare

\section{Caracterización de resultados generales}

En síntesis:

- $\quad$ Se mostraron párrafos coincidentes con otros textos, en los cuales no se expresa la procedencia de la información, a pesar de que resulta notable el parecido y el proceso de "copie y pegue".

- $\quad$ Se encontraron partes de textos similares con otros, a los que se les aplican cambios mínimos de palabras en la redacción, con lo cual el texto podría alcanzar la categoría de parafraseo inadecuado, sin embargo, no se cita como tal.

- Se identificaron párrafos copiados textualmente y con la inserción de una idea original. Aunque a veces la información ofrecida corresponde a conocimiento general en la materia, resulta clara la coincidencia con otros textos, no en la información -que sería completamente válida- sino en la redacción.

- Algunos párrafos evidenciaron una gran coincidencia entre el texto del artículo en cuestión y otro, incluso en la organización del discurso. Se toma todo un apartado de un texto y se reproduce tal cual, con cambios mínimos. No se señala fuente ni de parafraseo ni textual. En otros momentos se reescribe todo un párrafo de enumeración constituido a reglón seguido, se cambia de estructura (cada elemento enumerado en línea aparte y con viñetas), se modifica la puntuación, para adecuarla a la nueva estructura, y no se anota ni como cita textual ni como parafraseo.

- Aunque se hacen algunos pequeños cambios, se copia de manera tan textual que incluso se trasladan las citas anotadas en la fuente. Si el texto hubiera indicado su origen, debió considerarlas citas de segundo orden e indicarlas, en el párrafo como tal. De la forma en que aparecían, si no se percibe que el texto es copia de otro, se leerían como citas de parafraseo en el texto en cuestión, pero deberían aparecer en las referencias bibliográficas. No obstante, estas citas no aparecen en el apartado de referencias, lo cual parece evidenciar que no fueron consultadas para el trabajo, sino que se tomaron del texto fuente. Aunque el autor del texto fuente sí aparece en las referencias, en esta parte del escrito en cuestión debió consignarse que esta parte del texto era tomada textualmente o, al menos, parafraseada, lo cual no se indica.

- Por otro lado, aparecieron textos muy coincidentes con variedad de documentos de la red, posiblemente muy visitados para esta temática, de manera que se evidenciaron muchas copias de lo mismo, sin las debidas referencias, la mayoría de las veces. Pareciera que esta es una práctica común en esta comunidad académica. Al respecto cabe la pregunta: ¿quién le copia a quién? 
- Todos los anteriores casos resumidos, según lo conceptualizado en este informe, clasifican en plagio directo, pues se ha omitido la autoría, no se indica con comillas lo tomado y se realizan cambios mínimos en textos ajenos que se presentan como originales.

- De igual manera, se anotó que en otros artículos de su misma autoría, quien escribió los textos en cuestión se copia de estos, sin autocitarse. Esta conducta se define como autoplagio, concepto muy reciente y al que habrá que dársele difusión, para ayudar así a la comunidad académica a evitarla.

\section{Reflexión de cierre}

En la práctica académica constantemente se recurre al legado constituido por una comunidad. En la producción textual que implica este ámbito, en general, es difícil encontrar que se copie toda una obra, pero sí es frecuente que, de manera ingenua, quisiera creerlo, se tomen textos parciales que no se anotan como ajenos o se inscriben de forma inadecuada.

Quienes escriben deben informarse sobre los protocolos de citación y capacitarse en la elaboración de paráfrasis, de manera que limitaciones en el manejo del código escrito no los lleven a incurrir en plagio. Por otro parte, y fundamentalmente, deben acogerse a los parámetros éticos establecidos en relación con el respeto al texto ajeno.

Por otro lado, los consejos editoriales, sus cuerpos de dirección, de edición y de evaluación de escritos deben establecer controles que les aseguren que sus medios de difusión no publiquen textos con este uso indebido.

Esta colaboración no pretende fungir como acusadora, sino llamar la atención sobre uno de los cuidados necesarios en el documento que se escribe y se publica. Se espera que sea de provecho para iniciar una discusión al respecto.

\section{Referencias}

American Psychological Asociation (APA). (2010). Manual de publicaciones de la American Psychological Asociation (Trad. M. Guerra). ( $3^{\circ}$ ed.). México: Editorial El Manual Moderno.

Balbuena, P. V. (s. f. ). El plagio como ilícito penal. Especial referencia al "auto plagio". Ventana Legal Revista. Recuperado de http://www.ventanalegal.com/revista ventanalegal/plagio ilicito.htm

Barrón, A. (2010). Detección automática de plagio en texto, una breve reseña. Grupo Fivas. Recuperado de http://grupofivasa.blogspot.com/2010/01/deteccion-automatica-deplagio-en-texto.html 
Comas, R. y Sureda, J. (2007). Ciber-plagio académico. Una aproximación al estado de los conocimientos. Revista TEXTOS de la CiberSociedad, 10. Recuperado de http://www. cibersociedad.net/textos/articulo.php?art=121

Laboratorio de Lingüística Forense [ForensicLab]. (s. f.). Peritaje lingüístico. Barcelona: Universitat Pompeu Fabra. Institut Universitari de Lingüística Aplicada. Recuperado de http://www. iula.upf.edu/forensiclab/fmetodes.htm

Sánchez, M. P. (diciembre, 2006). Nociones básicas en materia de propiedad intelectual. Periférica, 7, 67-89. Recuperado de http://www.uca.es/web/actividades/periferica/documentos/ periferica07pdf

Tello, E. y Zepeda, B. (s. f.). El plagio académico. Presentación basada en el documento "Academic Plagiarism Defined", de Irving Hexham (Presentación PowerPoint). Recuperado de http:// www.ucalgary.ca/ hexham/study/plag.html 